\title{
RESPONSABILIDADE PRÉ-CONTRATU̇AL NO CÓDIGO DE DEFESA DO CONSUMIDOR: ESTUDO COMPARATIVO COM A RESPONSABILIDADE PRÉ-CONTRATUAL NO DIREITO COMUM.
}

\author{
Antonio Junqueira de Azevedo \\ Professor Titular de Direito Civil da Faculdade de Direito da USP
}

\begin{abstract}
Resumo:
$\mathrm{O}$ artigo se inicia com a observação de que, tendo em vista a demora na atualização do Código Civil, foi o Código de Defesa do Consumidor que acabou favorecendo a modernização de todo o sistema do Direito privado brasileiro; isto se deu graças especialmente à consagração legislativa da idéia de boa-fé objetiva (a "cláusula geral da boa-fé" de inúmeros Códigos europeus). Sobre a responsabilidade pré-contratual, o CDC, à semelhança do Código Civil, não trouxe capítulo próprio; na fase das negociaçð̃es preliminares, a questão da ruptura abusiva e alguns dos chamados deveres prévios não foram contemplados. Em compensação, o dever de informar, com a publicidade e o dever de proteção mereceram, sob a ótica da boa-fé objetiva, preceitos claros. $\mathrm{Na}$ fase da oferta, a informação e a publicidade "suficientemente precisa" foram equiparadas à proposta de contrato e, assim, esses atos vinculam o agente de forma conclusiva.
\end{abstract}

\begin{abstract}
:
The article starts with the remark that, due to the delay in updating the Brazilian Civil Code, was the new Consumer Protection Code (CDC - Código de Defesa do Consumidor) that favored the modernization of the whole Brazilian private law system; this modernization took place thanks to the successful adoption into legislation of the standard of the objective good faith (the "general clause of good faith" of European Contract Law). Concerning the precontractual responsability, similarly to the Brazilian Civil Code, the CDC did not include a specific chapter. In the preliminary negotiations phase, the issue of abusive disruption and some of the so-called prior obligations were not contemplated. On the other hand, both the obligation to inform the consumer through advertising and the obligation of protection health, safety and economic interests of the consumer have received clear precepts under the standpoint of the objective good faith. Finally, in the offer phase, the information and the "sufficiently precise" advertising were considered as contract proposal; therefore, these acts oblige the agent conclusively.
\end{abstract}




\author{
SUMÁRIO \\ Introdução \\ I - Fundamento da responsabilidade pré-contratual. \\ II - A boa-fé objetiva. \\ III - A fase das negociações: os deveres dos candidatos a contratantes e a ruptura \\ abusiva. \\ IV A fase da oferta. A informação e a publicidade "suficientemente" precisa. \\ Conclusão
}

Introdução

A demora na atualização do Código Civil fez com que o Código de Defesa do Consumidor, de uma certa forma, viesse preencher a vasta lacuna que, no campo do direito privado brasileiro, a doutrina e a jurisprudência percebiam há muito tempo. Na impossibilidade de encontrar, no velho Código Civil, base para o desenvolvimento teórico do que há de mais apto para transformar o sistema fechado em sistema aberto - por exemplo, a referência expressa a cláusulas gerais, como a da boa-fé, e a princípios jurídicos, como o de exigência de igualdade real nos negócios jurídicos -, é no Código de Defesa do Consumidor que se pode encontrar um ersatz do Código Civil que não veio ou, no mínimo, um ponto de apoio para alavancar a atualização, eis que tudo que ocorre num microssistema, como o do consumidor, deve repercutir, dependendo do esforço do "estamento jurídico", em todo o ordenamento.

Sobre o tema "responsabilidade pré-contratual", o Código de Defesa do Consumidor, apesar de sua ambição de ser código, não trouxe, à semelhança do Código Civil, um capítulo específico; entretanto, há nele várias disposições que permitem uma construção teórica, como passamos a expor.

I - Fundamento da Responsabilidade Pré-Contratual.

Ressalvada a questão da oferta que, no Direito brasileiro, é ato unilateral criador de obrigação (art. 1.080, do CC), uma primeira grande questão sobre a responsabilidade pré-contratual é a de seu fundamento: este, nem parece ser contratual, porque ainda não há contrato, nem parece ser conveniente qualificá-lo 
como extracontratual, eis que, estando os candidatos a contratantes em negociações, têm eles, entre si, deveres específicos por exemplo, o de prestar esclarecimentos um ao outro; ora, um dever específico é como que um vínculo jurídico entre duas pessoas e não se assemelha ao dever genérico de não-prejudicar a outrem - alterum non laedere - do art. 159, do CC.

Um exame do Direito comparado também não ajuda na solução da dúvida. França e Alemanha se opõem; na Alemanha, onde a responsabilidade contratual é mais aperfeiçoada, é nesta que a responsabilidade pré-contratual se inclui; na França em que, inversamente, a responsabilidade civil é tema de grande desenvolvimento, a responsabilidade pré-contratual está nela integrada. Conforme se trate de um ou outro fundamento, poderá haver grande diferença de tratamento: dolo ou culpa presumidos versus dolo ou culpa a provar; danos emergentes e lucros cessantes "por efeito direto e imediato" do descumprimento (art. 1.060, do CC) versus danos emergentes e lucros cessantes totais; lucros previsíveis versus quaisquer lucros; capacidade contratual versus capacidade delitual; prazos de prescrição variáveis versus prazo de prescrição de cinco anos; etc. O Código de Defesa do Consumidor nada esclareceu sobre esses pontos.

Alguns autores sustentam a idéia do tertium genus; haveria, além da responsabilidade contratual e extracontratual, a pré-contratual. Já houve também quem, entre os dois territórios inimigos, o contratual e o extracontratual, estendesse uma "terra de nessuno", representada pela responsabilidade pré-contratual (Busnelli, apud "Travaux" da Association Henri Capitant, Tomo XLIII, 1992, p. 140). Interessante é a tomada de posição (tomada de posição?) do Supremo Tribunal Federal da Suíça; depois de optar, durante anos, ora por um, ora por outro fundamento, decidiu: "não há lugar para distinguir entre obrigações contratuais $e$ extracontratuais; ... a questão a solucionar não é a da natureza jurídica da responsabilidade; trata-se somente de determinar de quais modalidades, quanto às suas condições e conteúdo, depende o crédito de perdas e danos nascido de uma relação de negociações prévias; esse problema deve ser resolvido separadamente para cada modalidade, de maneira que uma solução apropriada ao caso concreto seja encontrada" ("Travaux", da Association Henri Capitant, Tomo XLIII, 1992, p. 205). Pessoalmente, tendo em vista nossa idéia de que o contrato é um processo (uma sucessão de "tempos" como ocorre com o próprio negócio jurídico), que vai, desde a fase pré-contratual, passando à fase contratual, distribuída em três fases menores (conclusão do contrato, eficácia do contrato e execução/adimplemento do 
contrato), e indo até a fase pós-contratual, todas subordinadas à boa-fé objetiva, pensamos que, embora surgindo de ato ilícito, a responsabilidade pré-contratual, por se tratar de descumprimento de deveres específicos, gerados pela boa-fé objetiva, deva se submeter ao tratamento da responsabilidade contratual; haverá lugar, portanto, para presunção de culpa, capacidade contratual, prescrição idem, etc. Os danos emergentes e os lucros cessantes devem ser os do interesse negativo.

A fase pré-contratual pode ser decomposta, singelamente, em duas fases menores: a das negociações e a da oferta. Evidentemente, conforme o comportamento das partes, podem também surgir outras fases menores, por causa de possíveis contratos prévios, quer para organizar as negociações por exemplo, estipulando quem arcará com as despesas de preparo da documentação , quer para fixar pontos progressivamente acertados do contrato futuro. O mesmo se diga, se for feito um contrato preliminar, ou pré-contrato. Considerando, porém, as limitações do presente trabalho, vamos nos limitar àquelas duas fases, sobre as quais, aliás, o CDC traz algumas disposições; a exposição de ambas será precedida de ligeiras considerações sobre a boa-fé objetiva.

\section{A Boa-Fé Objetiva.}

À medida que vem diminuindo a intensidade do conflito entre autonomia da vontade, de um lado, e intervenção estatal, de outro, temos a impressão que o Direito privado, parcialmente liberto daquela questão ideológica, vem adquirindo novo alento, especialmente nos temas relativos aos negócios jurídicos e aos contratos; nas novas análises, a cláusula geral da boa-fé objetiva representa, hoje, uma das linhas mais importantes. Não se trata, como é óbvio, da velha boa-fé subjetiva, entendida como um estado psíquico de conhecimento ou desconhecimento, de intenção ou falta de intenção, que serve para aquisição de direitos, como em matéria de frutos e benfeitorias (arts. 510 e 516, do CC), de usucapião (art. 500, do CC), ou de aquisição a non domino (art. 622, do CC), isto é, em geral, de temas de direito das coisas embora também possam ser lembrados casos de direito de família (por ex., o casamento putativo) e de direito das obrigações (por ex., o credor putativo). A cláusula geral da boa-fé objetiva é norma de comportamento que, transformada em artigo de lei, está positivada em vários Códigos Civis (por ex., art. 1.134, do Código Civil francês; § 242, do BGB; art. 1.337, do CC italiano; art. 227, do CC português). 
Uma das mais interessantes disposições sobre a boa-fé objetiva, no direito comparado, é a do art. $2^{\circ}$, do Código Civil suíço: "Todos devem exercer direitos e executar suas obrigações segundo as regras da boa-fé. O, abuso de direito não é protegido pela lei" O preceito do $\mathrm{CC}$ suiço é tanto mais interessante quanto aproxima a boa-fé objetiva do abuso de direito e, marcando bem as questões, define e delimita o papel da boa-fé subjetiva somente no artigo seguinte (no art. $3^{\circ}$ ).

$\mathrm{O}$ art. $4^{\circ}$, III, do Código de Defesa do Consumidor também positivou a idéia de boa-fé objetiva, in verbis: “... atendidos os seguintes princípios: harmonização dos interesses dos participantes das relações de consumo ... sempre com base na boa-fé e equilibrio nas relações entre consumidores e fornecedores"; as referências à boa-fé objetiva são tão fortes, aliás, no CDC (além do art. $4^{\circ}$ também art. 51, IV), que não é temerário dizer que a idéia de boa-fé constitui a inspiração principal da legislação sobre defesa do consumidor no Brasil.

A boa-fé objetiva constitui, no campo contratual - sempre tomando-se o contrato como processo, ou procedimento norma que deve ser seguida nas várias fases das relações entre as partes; o pensamento, infelizmente, ainda muito difundido, de que somente a vontade das partes conduz o processo contratual, deve ser definitivamente afastado. É preciso que, na fase pré-contratual, os candidatos a contratantes ajam, nas negociações preliminares e na declaração da oferta, com lealdade recíproca, dando as informações necessárias, evitando criar expectativas que sabem destinadas ao fracasso, impedindo a revelação de dados obtidos em confiança, não realizando rupturas abruptas e inesperadas das conversações, etc. Aos vários deveres dessa fase, seguem-se deveres acessórios à obrigação principal na fase contratual quando a boa-fé serve para interpretar, completar ou corrigir o texto contratual - e, até mesmo, na fase pós-contratual, a boa-fé também cria deveres, os posteriores ao término do contrato - são os deveres post pactum finitum, como o do advogado de guardar os documentos do cliente, o do fornecedor de manter a oferta de peças de reposição, o do patrão de dar informações corretas sobre ex-empregado idôneo, etc. Sobre todas essas questões, há a já-referida publicação dos trabalhos da Association Henri Capitant, "La Bonne Foi" "Travaux" Tomo XLIII, 1992, em que os relatórios brasileiros foram devidos ao professor Arnoldo Wald, sobre a execução do contrato, e a mim mesmo, sobre a formação do contrato; há também monografias e, entre elas, os livros do professor Menezes Cordeiro, "Da Boa-Fé no Direito Civil", Coimbra, Almedina, 1984, e "Da Pós-Eficácia das Obrigações", Lisboa, s.c.p., 1984. Em qualquer uma das fases contratuais, a cláusula geral da boa- 
fé, como norma de comportamento, cria, para as partes, deveres positivos e negativos; estão, entre os primeiros, os deveres de colaboração, inclusive de informação ou seja, as partes, no contrato, formam como que um microcosmo, ou pequena sociedade, como já dizia Demogue, na década de 30 , e, entre os segundos, os deveres de lealdade, especialmente o de manter sigilo.

$\mathrm{O}$ trecho de Demogue ("Traité des Obligations en général", $3^{\mathrm{a}}$ ed., Paris, Rousseau, 1931, v. VII, n 3, p. 9) é o seguinte: "Il nous semble cependant que les conséquences qu'on a tirées de l'idée de bonne foi entre contractants sont encore assez pauvres et que le contrat moderne peut être conçu d'une façon plus vivante et plus complexe en faisant sortir de l'idée de bonne foi de nouveaux rameaux. Quand on lit les civilistes, il semble que le contrat ayant engendré au profit d'une partie ou des deux une créance, celle-ci déroule logiquement ses conséquences par des droits divers qui en sortent: droit à exécution, droit à des dommages-intérèts, etc.. En réalité le contrat s'exécute autrement. Les contractants forment une sorte de microcosme. C'est une petite société où chacun doit travailler dans un but commun qui est la somme des buts individuels poursuivis par chacun, absolument comme dans la société civile ou commerciale" Há, portanto é o que se reconhece hoje -, uma série de deveres e conseqüentes comportamentos que circundam, se for possível falar assim, o simples texto do contrato.

A boa-fé objetiva, estabelecendo os deveres de comportamento que as partes devem seguir nas fases pré-contratual, contratual e pós-contratual, pode ser considerada, além disso, como sendo princípio geral de Direito, não expresso no Código Civil, mas incorporado ao Direito brasileiro como um todo, por força do art. $4^{\circ}$, da Lei de Introdução ao Código Civil (nesse sentido, Arnoldo Wald, obra citada, p. 255 e "Obrigações e Contratos" $10^{\mathrm{a}}$ ed., São Paulo, Revista dos Tribunais, 1992 , p. 155 a 157). Como quer que seja, a admissão da boa-fé, no nosso ordenamento, não se limita, pois, ao microssistema do direito do consumidor mas a norma deve ser aplicada pela jurisprudência, no seu papel de agente intermediário entre a lei e o caso, a todo o direito (inclusive ao Direito público). A boa-fé objetiva é, do ponto de vista do ordenamento, o que os franceses denominam "notionquadre" isto é, uma cláusula geral que permite ao julgador a realização do justo concreto, sem deixar de aplicar a lei.

Em tese, a norma da boa-fé pode atuar, acarretando responsabilidade pré-contratual, quer quando o contrato previsto não se concretiza, porque houve ruptura abusiva, quer quando o contrato se conclui mas houve descumprimento de 
dever na fase pré-contratual (por ex., insider que se aproveita de suas informações), quer, finalmente, quando o contrato se realiza mas é nulo e um dos contratantes sabia da causa da nulidade ( $\hat{e}$, aliás, a hipótese inicialmente imaginada por Jhering para criar a teoria da culpa in contrahendo).

III A Fase das Negociações: Os Deveres dos Candidatos a Contratantes e a Ruptura Abusiva.

Nesta fase, para efeitos de exposição, pode-se dizer que são quatro os grandes temas. A norma da boa-fé cria três deveres principais: o de lealdade, consistente, aqui, principalmente num dever de confidencialidade, isto é, de manter o sigilo das informações obtidas, e dois, de colaboração, que são, basicamente, o de bem informar o candidato a contratante sobre o conteúdo do contrato e o de nãoabusar ou, até mesmo, de se preocupar com a outra parte (dever de proteção). Além desses três deveres, o quarto tema é o da ruptura abusiva das negociações.

Ora, o CDC não se refere especificamente a negociações ou tratativas. Trata, porém, de dois dos temas citados, isto é, trata largamente do dever de informar - especialmente na seção sobre publicidade - e do dever de não-abusar, ou de proteção, sobre o qual há também muitas regras, principalmente na seção "Das Práticas Abusivas" (os incisos I a V, do art. 39 dizem respeito à fase pré-contratual). Sobre os outros dois temas, há omissão; nada consta sobre o dever de confidencialidade; o inciso VII, do art. 39, sobre repasse de informações depreciativas, não é o caso, eis que não se trata de dever prévio de confidencialidade. $\mathrm{O} \mathrm{CDC}$, devido à natureza das relações de consumo, mais propícias aos contratos de adesão, não fez previsão de inconfidência na fase précontratual mas a hipótese pode ocorrer, por ex., médico plástico, que divulga o fato de artista conhecido o haver procurado; ou advogado, que revela ter sido consultado por político que pretendia se divorciar; etc.

Há também omissão do CDC, aqui menos justificável, sobre ruptura das negociaç̃̃es. A possibilidade de quebra da norma da boa-fé pode ocorrer, tanto por parte do fornecedor, quanto do consumidor; os deveres existem para ambas as partes. A hipótese do pedido de reserva de produto, antes de qualquer contrato, pode servir para exemplificar um e outro caso; o consumidor que, despertada a confiança do fornecedor, depois a frustra, não indo buscar o produto, pode causar prejuízo; o 
fornecedor, por sua vez, se promete a reserva e, depois, não a faz, também pode causar dano ao consumidor.

Ainda sobre a ruptura, é ponto pacífico, na doutrina e na jurisprudência, que as negociações devem ser interrompidas assim que um dos candidatos a contratante tenha certeza da inutilidade do prosseguimento. Isto poderia ocorrer nas relações de consumo, todas as vezes, por exemplo, que um incorporador, ou um possível adquirente de imóvel, tem certeza de que o financiamento, com que contava, não será dado. Segundo o CC italiano (art. 1.338), pode-se dizer que, conforme o caso, as negociações nem sequer deveriam começar. " $A$ parte que, conhecendo ou devendo conhecer a existência de uma causa de invalidade do contrato, dela não deu notícia à outra, é obrigada a ressarcir o dano que esta sofreu, por ter, sem culpa, confiado na validade do contrato"

Dito isso sobre as omissões, passemos aos dois deveres previstos no $\mathrm{CDC}$, o de informar e o de proteção. O dever de informar tem graus; conforme a situação, há simples dever de esclarecer ou, mais fortemente, o de aconselhar ou, até mesmo, se houver riscos, o de advertir. Se o fornecedor é um profissional, é provável que deva cumprir os três graus (basta pensar numa venda de material sofisticado ou no fornecimento de serviços de médico ou advogado). Além disso, conforme a fase das negociações, se inicial ou final, o dever de informar, ainda que limitado somente ao esclarecer, pode ter conteúdo menor ou maior (= esclarecer mais, ou menos).

A omissão de informação essencial constitui dolo; o art. 94, do CC, que trata do dolo por omissão, interpretado a contrario sensu, já previa o dever de informar e o CDC tornou esse dever ainda mais explícito, ao incluí-lo entre os "direitos básicos" do consumidor. Art. 60: "São direitos básicos do consumidor: III a informação, adequada e clara sobre os diferentes produtos e serviços, com especificação correta de quantidade, características, composição, qualidade e preço, bem como sobre os riscos que apresentam"

Todavia, especialmente na fase pré-contratual dos contratos de aquisição de bens, o dever de informar se limita, a nosso ver, ao conteúdo do contrato, especialmente às qualidades essenciais do objeto, e não, à oportunidade ou vantagem do contrato (isto é, se a mercadoria, dentro em pouco, vai ficar mais barata ou se há, no mercado, outra superior pelo mesmo preço); quanto a esses dois pontos, vale a velha máxima "caveat emptor" "cuide-se o comprador". Admitir dever de informar também sobre a oportunidade ou a vantagem desses contratos é querer transformar o fornecedor em assistente social. 
O dolo nos negócios jurídicos, como meio ou artifício de indução em erro, sempre foi ato ilícito, porque, ainda quando acidental, acarreta a responsabilidade por perdas e danos (art. 93, do CC). Agora, esse ato ilícito pode constituir até mesmo crime (art. $7^{\circ}$, VII, da Lei n. 8.137, de 1990): "Constitui crime contra as relações de consumo: VII - induzir o consumidor ou usuário a erro, por via de indicação ou afirmação falsa ou enganosa sobre a natureza, qualidade de bem ou serviço, utilizando-se de qualquer meio, inclusive a veiculação ou divulgação publicitária"

A publicidade, no CDC, é o novo, neste tema do dever de informar; tratada na Seção III do Capítulo V ("Das Práticas Comerciais"), embora seja direito do fornecedor, tem ela regras estritas: deve ter dados fáticos, técnicos e científicos que dêm sustentação à mensagem ( $\S$ único do mesmo artigo) e, principalmente, não pode ser enganosa (art. 37): "É proibida toda publicidade enganosa ou abusiva. $\S$ $1^{\circ}$ É enganosa qualquer modalidade de informação ou comunicação de caráter publicitário, inteira ou parcialmente falsa, ou, por qualquer outro modo, mesmo por omissão, capaz de induzir em erro o consumidor a respeito da natureza, características, qualidade, quantidade, propriedades, origem, preço e quaisquer outros dados sobre produtos e serviços" Vê-se bem que a publicidade até mesmo verdadeira, tal seja o contexto, pode ser enganosa.

Além disso, a publicidade não pode ser abusiva (cf. $\S 2^{\circ}$ do mesmo art. 37) e, com isso, já se passa ao dever de proteção: "É abusiva, dentre outras, a publicidade discriminatória de qualquer natureza, a que incite à violência, explore o medo ou a superstição, se aproveite da deficiência de julgamento e experiência da criança, desrespeita valores ambientais, ou que seja capaz de induzir o consumidor a se comportar de forma prejudicial ou perigosa à sua saúde ou segurança" Também sobre produtos, o art. 12, em sua parte final, tem em vista o dever de proteção, verbis "informações insuficientes ou inadequadas sobre sua utilização $e$ riscos", por ex., bulas de remédio pouco esclarecedoras. O mesmo se diga, sobre serviços, no art. 14.

Ao tratar das práticas abusivas, percebe-se claramente que o CDC, consagra o dever de proteção. Art. 39 - "É vedado ao fornecedor de produtos ou serviços: IV - prevalecer-se da franqueza ou ignorância do consumidor, tendo em vista sua idade, saúde, conhecimento ou condição social, para impingir-lhe seus produtos ou serviços; $V$ - exigir do consumidor vantagem manifestamente excessiva" É a lesão qualificada, com nova roupagem, isto é, os dois pressupostos 
da lesão qualificada, exigidos cumulativamente em alguns ordenamentos e no Projeto de Código Civil (Projeto n. 634 - B), estão, no CDC, previstos isoladamente.

IV - A Fase da Oferta. A Informação e a Publicidade "Suficientemente Precisa"

Entre nós, desde o advento do $\mathrm{CC}$, e ao contrário do que ocorre em inúmeros países da família romano-germânica, nunca houve dificuldade à aceitação de que os atos unilaterais criam obrigações ( v. Titulo VI, "Das Obrigações por Declaração Unilateral de Vontade" do Livro "Do Direito das Obrigações"). Em matéria de oferta, a disposição do art. 1.080 também nunca deixou margem à dúvida sobre seu caráter vinculante: "A proposta de contrato obriga o proponente, se o contrário não resultar dos termos dela, da natureza do negócio, ou das circunstâncias do caso" Portanto, no Direito brasileiro, ainda que a oferta esteja na fase pré-contratual, as questões que dela surgem são, inegavelmente, de responsabilidade contratual (por motivos óbvios, seria melhor dizer, de responsabilidade negocial).

O CDC foi ainda mais longe que o CC na atribuição de efeitos jurídicos à oferta. Em primeiro lugar, não há previsão de exceções sobre seu caráter vinculante; no sistema do CDC, toda oferta obriga. Em segundo lugar, o CDC equiparou, à oferta, a informação ou a publicidade "suficientemente precisa" (art. 30), verbis: "Toda informação ou publicidade, suficientemente precisa, veiculada por qualquer forma ou meio de comunicação com relação a produtos e serviços oferecidos ou apresentados, obriga o fornecedor que a fizer veicular ou dela se utilizar e integra o contrato que vier a ser celebrado"

A conseqüência jurídica dessas disposições é que, dada a informação, ou feita a publicidade, desde que "suficientemente precisa", ou apresentada a oferta, o fornecedor cria um direito potestativo para o consumidor; este pode aceitar, ou não, o negócio a que se propõe; o fornecedor está em pura situação de sujeição. Se houver aceitação pelo oblato, o contrato está concluído e o consumidor pode "exigir o cumprimento forçado da obrigação, nos termos da oferta, apresentação ou publicidade" (art. 35, I ). Não há sequer possibilidade de retratação do proponente; sob esse aspecto, a solução do CDC é a mésma que o CC, no art. 1.514, prevê para a promessa de recompensa com prazo determinado: "Se, porém, houver assinado prazo à execução da tarefa, entender-se-á que (o promitente) renuncia o arbitrio de retirar, durante ele, a oferta" 
É interessante observar que, do ponto de vista teórico, o suporte fático da oferta é declaração negocial e, portanto, ela é negócio jurídico. Já a informação ou a publicidade suficientemente precisa não contêm declaração negocial, mas são somente atos legalmente equiparados à oferta; logo, não são negócios jurídicos, e sim, atos a que a lei atribui efeitos negociais (à semelhança das chamadas "relações contratuais de fato"). Dessas diferenças, pode surgir uma série de conseqüências práticas, especialmente em matéria de vícios do consentimento (erro, dolo, coação).

Quanto ao descumprimento da oferta, deve-se entender, no sistema do $\mathrm{CC}$, que há uma diferença entre obrigatoriedade e revogabilidade, isto é, a oferta, ressalvadas as exceções, obriga (art. 1.080), mas, antes de aceitação, pode ser revogada, - quando, então, o contrato não se fará e o inadimplemento da oferta se converterá em perdas e danos. Essas perdas e danos não são, evidentemente, as do contrato, e sim, as do interesse negativo, ou seja, as perdas e danos consistirão, então, na diferença entre o patrimônio com que o candidato a contratante está e o com que estaria, se não tivesse havido a oferta. Somente nos casos de oferta a prazo ou da oferta com cláusula de irrevogabilidade é que se pode dizer que, se se admitir a retratação de oferta antes da aceitação e, portanto, se não for obedecido o vínculo da oferta pelo proponente (não é a melhor solução; a retratação não deveria ser admitida), o oblato terá direito às perdas e danos do interesse positivo, isto é, as do contrato não-concluído. No caso do $\mathrm{CDC}$, diferentemente, as perdas e danos são sempre as do interesse positivo, porque o próprio contrato é que, no caso, é considerado não-cumprido; a bem-dizer, portanto, no $\mathrm{CDC}$, não há sequer a possibilidade de descumprimento da oferta, eis que, o contrato, se houver aceitação, é sempre reputado como concluido (art. 35, I, II e III ).

\section{Conclusão}

A responsabilidade pré-contratual, resultante de prejuízos causados na primeira fase do processo contratual fase pré-contratual, embora resulte de ato ilícito, provém de descumprimento de dever específico imposto pela norma da boafé; por isso, obedece às regras da responsabilidade contratual, antes que da responsabilidade extracontratual.

No CDC, a responsabilidade pré-contratual não foi sistematizada; considerando, porém, seus dois momentos fundamentais, o das negociações e o da oferta, temos que, quanto ao primeiro, os deveres de informar o candidato a 
contratante e o de proteção estão previstos em suas conexões com os direitos básicos do consumidor e com a publicidade. Quanto ao segundo, tendo em vista que, no CDC, a oferta sempre vincula, e de forma cabal, não há possibilidade de seu descumprimento; o contrato, se o consumidor o desejar, é sempre considerado concluído, seguindo-se, então, as regras da responsabilidade contratual. 